\title{
Sensitivity Theory for Reactor Thermal-Hydraulics Problems
}

\author{
E. M. Oblow
}

OAK RIDGE NATIONAL LABORATORY OPERATED BY UNION CARBIDE CORPORATION - FOR THE DEPARTMENT OF ENERGY 


\section{DISCLAIMER}

This report was prepared as an account of work sponsored by an agency of the United States Government. Neither the United States Government nor any agency Thereof, nor any of their employees, makes any warranty, express or implied, or assumes any legal liability or responsibility for the accuracy, completeness, or usefulness of any information, apparatus, product, or process disclosed, or represents that its use would not infringe privately owned rights. Reference herein to any specific commercial product, process, or service by trade name, trademark, manufacturer, or otherwise does not necessarily constitute or imply its endorsement, recommendation, or favoring by the United States Government or any agency thereof. The views and opinions of authors expressed herein do not necessarily state or reflect those of the United States Government or any agency thereof. 


\section{DISCLAIMER}

Portions of this document may be illegible in electronic image products. Images are produced from the best available original document. 


\title{
Printer in the I Inited States of America. Availablo from National Technical Information Service
}

U.S. Department of Commerce 5285 Port Royal Road, Springfield, Virginia 22161

Price: Printed Copy $\$ 5.25$; Microfiche $\$ 3.00$

\begin{abstract}
This report was prepared as an account of work sponsored by an agency of the United States Government. Neither the United States Government nor any agency thereof, nor any of their employees, contractors, subcontractors, or their employees, makes any warranty, express or implied, nor assumes any legal liability or responsibility for any third party's use or the results of such use of any information, apparatus, product or process disclosed in this report, nor represents that its use by such third party would not-infringe privately owned rights.
\end{abstract}


ORNL/TM-6303

Distribution Category UC-79d

Breeder Reactor Physics

Contract No. W-7405-eng-26

Neutron Physics Division

SENSITIVITY THEORY FOR

REACTOR THERMAL-HYDRAULICS PROBLEMS

E. M. Oblow

Date Published - July 1978

OAK RIDGE NATIONAL LABORATORY

Oak Ridge, Tennessee 37830

operated by

UNION CARBIDE CORPORATION

for the

DEPARTMENT OF ENERGY 


\section{THIS PAGE}

\section{WAS INTENTIONALLY}

LEFT BLANK 
TABLE OF CONTENTS

Page No.

Abstract

Acknowl edgement

I. Introduction - 1

II. Theory for a General Transient Problem -.-.-- 3

III. Theory for a Steady-State Problem - 15

IV. Solution of a Sample Sensitivity Problem - 20

V. Sumimäày and lonclusions - 36 


\section{THIS PAGE}

\section{WAS INTENTIONALLY \\ LEFT BLANK}




\section{ABSTRACT}

A sensitivity theory based on reactor physics experience was successfully developed for a reactor thermal-hydraulics problem. The new theory is derived for the case of non-linear, transient heat and mass transfer in a typical reactor subassembly. Suitable adjoint equations for heat and fluid flow are presented along with methods for deriving the sources and boundary and final conditions for these equations. Expressions for the sensitivity of any integral temperature response to problem input data are also presented. The theory is applied to a sample problem describing the steady-state thermal-hydraulic conditions in a CRBR fuel channel. For this case, sensitivity coefficients are derived for several thermal response functions (i.e. peak clad and peak fuel temperature) for all physical input data (i.e. the heat transfer coefficient, thermal conductivities, etc.). A typical uncertainty analysis for peak clad and peak fuel temperature was also performed using uncertainty information about the physical data. Conclusions are drawn about the applicability of this approach to more general problems and the procedures for its implementation in conjunction with large safety or thermal-hydraulics codes are outlined. The method is also compared with currently used response surface techniques. 


\section{THIS PAGE}

\section{WAS INTENTIONALLY \\ LEFT BLANK}




\section{vi $i$}

\section{ACKNOWLEDGEMENT}

The author would like to thank G. F. Flanagan and E. T. Toml inson for their extensive help in understanding current theoretical and practical problems in fast reactor safety which motivated this study. Thanks are also due J. H. Marable and C. R. Weisbin for fruitful discussions concerning this new application of sensitivity and uncertainty analysis theory. The efforts of $\mathrm{C}$. Weber in developing numerical methods to solve the transient thermal-hydraulics problem were also of considerable help in this work. In addition, this work would not have been possible were it not for the strong encouragement and financial assistance provided by H. Aiter of the Division of Fast Reactor Safety at UUE. Finally, the author is indebted to Barbara Beem for typing the many drafts of this paper with all its equations and corrections. 


\section{Introduction}

Thermal-hydraulics calculations play an essential role in the design and safety analysis of nuclear reactor systems. The importance of these calculations has led to the development of a variety of large computer code systems which model heat, momentum, and mass transfer problems in great detail (e.g. the RELAP4 ${ }^{1}$ code for LWR design work and the SAS $3 A^{2}$ and MELT-III ${ }^{3}$ codes for fast reactor safety studies). Although these codes readily provide solutions to difficult design problems, the large number of physical effects they treat and their high running costs make them illsuited to applications of a parametric or survey nature. It is precisely this latter capability, however, that is needed to answer the typical sensitivity questions which arise frequently in all design and safety studies. Such difficult tasks as assessing confidence levels and uncertainties in calculated design parameters and determining the effect of changes in engineering data on the results of lengthy calculations are typical of the results required from any sensitivity analysis. To address these problems for a complex reactor system, it is essential to have available a sensitivity methodology that works within the existing design framework which relies so heavily on large computer code systems.

Currently, most successful deterministic solutions to the sensitivity problem are based in one form or another on response surface methods. 4 In this approach, a small subset of the data field needed as input for a large computer run is first chosen for study. Specific changes to be made in these data to address sensitivity questions are then derived from a variety of experimental design theories. ${ }^{5-7}$ A number of additional calculations are then made using these altered data sets to estimate the changes which occur in the calculated response of interest. These calculated results are then used to construct the response surface (i.e. the behavior of the response as a function of input data) which is fit with a simple functional form for later use.

With any of the experimental design theories, a large number of additional calculations are in general required to map the response surface for even a small data field (typically, 50 runs are needed to study 
the effects of changes in seven input data variables). To limit computer costs for these studies so that they are not excessive, fast-running versions of the large design codes are usually used (e.g. SACO ${ }^{8}$ was developed for SAS3A studies and a 12-volume version of RELAP4 ${ }^{9}$ is available for LWR sensitivity studies). Despite the sophisticated theories used and the extensive code development effort which has been undertaken, current sensitivity methods: (a) are still limited in scope by the choices which must be made beforehand, (b) require a great many time consuming calculations and (c) still rely on approximate methods for calculating sensitivities whose accuracy may be questionable if the rhanges in the data produce changes in the response which are either too large or too small.

To remedy the situation just outlined, this report explores the possibility of applying the differential sensitivity theory developed for radiation transport problems ${ }^{10}$ to the larger set of equations governing the thermal-hydraulics behavior of a reactor. This theory has the advantage of (a) being global in nature, in that the sensitivity to all data used in a calculation can be studied without a priori choices being made and (b) being fast and efficient, since only one additional set of equations needs to be solved for each response studied. The only major shortcoming of this theory is that to be really efficient it must be restricted to finding the linear behavior of the response surface in the vicinity of a sperific calculated design point. This drawback can be overcome in many cases by using high order interpolation schemes which combine the results of several design point calculations. In practice this is not a serious problem and the theory has been successfully applied in many fields of engineering and physics. ${ }^{11-22}$ With all the experience that has been acquired using this theory the advantages of the approach seem to far outweigh the disadvantages even for problems which are inherently non-linear in nature.

The purpose of this paper is to outline the development of a sensitivity theory for a general, yet tractable, problem in reactor core thermal-hydraulics and indicate how the theory can be used with existing codes for more applications-oriented research. In Section II this general theory is developed for a transient reactor thermal-hydraulics problem. The connection with the theory for steady-state problems is made in Section III. 
A general discussion of the results of a sample steady-state problem are discussed in Section IV and conclusions about the general applicability of the method are drawn in Section $V$.

\section{Theory for a General Transient Problem}

Consider the problem of heat transfer and fluid flow in a representative fuel-coolant channel of a nuclear reactor core. Figure 1 represents the cylindrically symmetric configuration of a typical reactor fuel rod (which includes the fuel pin, gap, and cladding) surrounded by a coolant which removes the fission heat generated in the fuel pin. If we consider a problem with negligible axial heat flow in the fuel and radially averaged fluid properties in the coolant channel (i.e. the use of bulk fluid properties), the following set of coupled non-linear differential equations can be used to represent the transient heat and mass balance in the system.

In the fuel rod, the radial heat conduction equation is:

$$
\rho \frac{\partial H}{\partial t}+\frac{1}{r} \frac{\partial}{\partial r}[r q]=Q
$$

where

$$
q \equiv-k \frac{\partial T}{\partial r}
$$

and $\rho$ is the density in $\mathrm{gm} / \mathrm{cm}^{3} ; H=\int_{0}^{T} c_{p} d T$ is the enthalpy in joules $/ \mathrm{gm}$; $k$ is the thermal conductivity in watts $/ \mathrm{cm}^{2}\left({ }^{\circ} \mathrm{C} / \mathrm{cm}\right) ; T(r, z, t)$ is the fuel temperature as a function of space and $t_{t i m e}$ in ${ }^{\circ} \mathrm{C} ; \mathrm{Q}(r, z, t)$ is the nuclear heat source in watts $/ \mathrm{cm}^{3} ; q(r, z, t)$ is the heat flux in watts $/ \mathrm{cm}^{2} ; 0 \leqslant r \leqslant R$; $0 \leq z \leq L$; and $0 \leqslant t \leqslant t_{f}$.

The boundary and initial conditions for the fuel region are:

$$
T(r, z, 0)=\hat{T}(r, z)
$$




$$
\begin{gathered}
q(\dot{0}, z, t)=-\left.k \frac{\partial T}{\partial r}\right|_{r=0}=0 \\
q(R, z, t)=-\left.k \frac{\partial T}{\partial r}\right|_{r=R}=h\left[T(R, z, t)-T_{c}(z, t)\right]
\end{gathered}
$$

where $\tilde{T}(r, z)$ is the steady-state temperature profile in the fuel in ${ }^{\circ} \mathrm{C} ; T_{C}(z, t)$ is the bulk coolant temperature at axial position $z$ and time $t ; h$ is the heat transfer coefficient in the coolant in watts $/ \mathrm{cm}^{2}{ }^{\circ} \mathrm{C}$; $0 \leqslant z \leqslant L$; and $0 \leqslant t \leqslant t_{f}$.

In the coolant channel, the axial heat convection equation is:

$$
\frac{\partial}{\partial t}\left[A \rho_{c} c_{p c}{ }^{\top}\right]+\frac{\partial}{\partial z}\left[w c_{p c}{ }^{\top}\right]=2 \pi R q(R, z, t)
$$

where, $A=\pi\left(R_{\max }^{2}-R^{2}\right)$ is the area of the coolant channel in $\mathrm{cm}^{2} ; \rho_{c}$ is the coolant density in $\mathrm{gm} / \mathrm{cm}^{3} ; w \equiv A \rho_{c} v_{z}$ is the coolant mass flow rate in $\mathrm{gm} / \mathrm{sec} ; \mathrm{C}_{\mathrm{pc}}$ is the coolant heat capacity in joules/gm ${ }^{\circ} \mathrm{C} ; \mathrm{T}_{\mathrm{c}}(z, t)$ is the coolant temperature in ${ }^{\circ} \mathrm{C}$ as a function of axial position $z$ and time $t$; $q(R, z, t)-h\left[T(R, z, t)-T_{C}(z, t)\right]$ is the heat flux into the coolant from the fuel rod wall in watts $/ \mathrm{cm}^{2}$; and $h$ is the heat transfer coefficient of the coolant in watts $/ \mathrm{cm}^{2}{ }^{\circ} \mathrm{C}$. The boundary and initial conditions in the coolant channel are:

$$
\begin{aligned}
& T_{C}(z, 0)-\tilde{T}_{C}(s) \\
& I_{c}(u, t)=T_{i}(t)
\end{aligned}
$$

where $\tilde{T}_{C}(z)$ is the steady-state axial temperature profile in the coolant and $I_{j}(t)$ is the inlet coolant temperature. 
For sensitivity purposes, the quantity of interest resulting from the solution of the above equations is called a system response. For this case it is convenient to define this response as an integral averaged temperature:

$$
P \equiv \iiint_{r} 2 \pi r f(r, z, t) T(r, z, t) d r d z d t+\iint_{z} g(z, t) T_{c}(z, t) d z d t
$$

where $f$ and $g$ are arbitrary weighting functions. They can be Heaviside or Dirac delta functions if needed to define useful results such as peak clad or peak fuel temperature and outlet coolant temperature.

The general problem in sensitivity analysis is to evaluate the rate of change of $P$ with respect to changes in any element, $\alpha$, of the data field used in Eqs. (1) and (6) to calculate $P$. That is, we want to know $d P / d \alpha$, the derivative of $P$ with respect to $\alpha$. For the sake of generality it is assumed that all the data are functionally dependent on $\alpha$ and either the coolant or fuel temperatures. That is, we assume the following forms for the input data: $c_{p}(T, \alpha), c_{p c}\left(T_{c}, \alpha\right), k(T, \alpha), h\left(T_{c}, \alpha\right), \rho(T, \alpha), A_{\rho}\left(T_{c}, \alpha\right)$, $w\left(T_{c}, \alpha\right)$, and $T_{i}(\alpha)$. Differentiating Eq. (9) with respect to $\alpha$ we find that the sensitivity derivative $\mathrm{dP} / \mathrm{d} \alpha$ is:

$$
\frac{d P}{d \alpha}=\frac{\partial P}{\partial \alpha}+\iint_{r} \int_{t} 2 \pi r f \frac{d T}{d \alpha} d r d z d t+\iint_{z} g \frac{d T_{C}}{d \alpha} d z d t
$$

where, $\partial P / \partial \alpha$, the "direct effect" term representing the explicit dependence of $P$ on $\alpha$ is:

$$
\frac{\partial P}{\partial \alpha} \equiv \iint_{r} \int_{t} 2 \pi r \frac{\partial f}{\partial \alpha} T d r d z d t+\iint_{z} \frac{\partial g}{\partial \alpha} T_{C} d z d t
$$

and the remaining two integral terms in Eq. (10) are the "indirect effect" terms representing the implicit dependence of $P$ on $\alpha$ through the temperatures which solve Eqs. (1) and (6). 
In order to evaluate Eq. (10), the behavior of $\mathrm{dT} / \mathrm{d} \alpha$ as a function of $r, z$, and $t$ and the behavior of $\mathrm{dT}_{c} / \mathrm{d} \alpha$ as a function of $z$ and $t$ must be known. Both of these functions obey partial differential equations similar to Eqs. (1) and (6) and they are functions of the quantity, da whose sensitivity is being studied. These equations will be developed in the next few paragraphs but only as a preliminary step in the development of the adjoint equations, which will eventually be used to evaluate the integral terms in Eq. (10). This adjoint approach is the basic strength of sensitivity theory since it avoids the necessity nf having to solve equations for $d T / d \alpha$ and $d T_{c} / d x$ which depend explicitly on $d r$ (as will bc seen later, the adjoint equations are independent of $d \alpha$ ). Such an approach is essential if a large number of input parameters are to bc studied (i.e. if $\alpha$ can take on many different definitions). It would become prohibitively expensive to keep resolving the basic partial differential equations for $d T / d \alpha$ and $d T_{c} / d \alpha$ over and over again to answer all the sensitivity questions which could arise.

As a step toward the development of the appropriate adjoint equations, the equations which $d T / d \alpha$ and $d T_{c} / d \alpha$ obey must first be derived. This is done easily by differentiating Eqs. (1) and (6) with respect to a about $\alpha=\alpha_{0}$ which represents a specific solution point in the response space. In pertorming this operation care must be taken to note those terms in the equation which are non-linear in nature. For these terms, functional derivatives ${ }^{10}$ must be used and this should be understood in the-notational shorthand which will be used in what follows.

Letting $\phi=d T / d u$ and $x \equiv d T{ }_{c} / d \alpha$, Eq. (1) can then be differentiated with resper.t. to $\alpha$, to get:

$$
\begin{aligned}
& \rho c_{p} \frac{\partial \phi}{\partial t}+\left[\frac{\partial\left(\rho c_{p}\right)}{\partial \alpha}+\frac{\partial\left(\rho c_{p}\right)}{\partial T} \phi\right] \frac{\partial T}{\partial t} \\
& -\frac{1}{r} \frac{\partial}{\partial r}\left[r k \frac{\partial \phi}{\partial r}+r \frac{\partial k}{\partial \alpha} \frac{\partial T}{\partial r}+r \frac{\partial k}{\partial T} \phi \frac{\partial T}{\partial r}\right]=\frac{\partial Q}{\partial \alpha}
\end{aligned}
$$


with initial and boundary conditions:

$$
\begin{gathered}
\phi(r, z, 0) \equiv \frac{\tilde{T}(r, z)}{\partial \alpha} \\
\left(\frac{\partial k}{\partial \alpha}+\frac{\partial k}{\partial T} \phi\right) \frac{\partial T}{\partial r}+\left.k \frac{\partial \phi}{\partial r}\right|_{r=0}=0 \\
{\left[\left(\frac{\partial k}{\partial \alpha}+\frac{\partial k}{\partial T} \phi\right) \frac{\partial T}{\partial r}+k \frac{\partial \phi}{\partial r}\right]_{r=R}=-\left(\frac{\partial h}{\partial \alpha}+\frac{\partial h}{\partial T} x\right)\left(T-T_{C}\right)-\left.h(\phi-x)\right|_{r=R}}
\end{gathered}
$$

Here the functional derivative notation is implied for all non-linear terms, so that for instance:

$$
\frac{\partial k}{\partial T} \phi \equiv \iint_{r^{\prime} z^{-} t^{-}} \frac{\partial k(T)}{\partial T^{\prime}\left(r^{\prime}, z^{\prime}, t^{\prime}\right)} \frac{d T\left(r^{\prime}, z^{\prime}, t^{\prime}\right)}{d \alpha} 2 \pi r^{\prime} d r^{\prime} d z^{\prime} d t^{\prime}
$$

Since $k(T)$ is a function of only the local temperature, the integrals in Eq. (16) are not essential for this particular problem--they should be noted only for the sake of generality.

Similarly, differentiating Eq. (6) with respect to a gives:

$$
\begin{aligned}
& \frac{\partial}{\partial t}\left[A_{\rho_{c} c_{p c} x}\right]+\frac{\partial}{\partial t}\left[\left(\frac{\partial\left(A_{\rho_{c}} c_{p c}\right)}{\partial \alpha}+\frac{\partial\left(A_{\rho_{c}} c_{p c}\right)}{\partial T_{c}} x\right) T_{c}\right]+\frac{\partial}{\partial z}\left[w c_{p c} x\right]+ \\
& \frac{\partial}{\partial z}\left[\left(\frac{\partial\left(w c_{p c}\right)}{\partial \alpha}+\frac{\partial\left(w c_{p c}\right)}{\partial T_{c}} \chi\right) T_{c}\right]=\left.2 \pi R\left[\left(\frac{\partial h}{\partial \alpha}+\frac{\partial h}{\partial T_{c}} \chi\right)\left(T-T_{c}\right)+h(\phi-x)\right]\right|_{r=R}
\end{aligned}
$$

with initial and boundary conditions:

$$
\begin{aligned}
& x(z, 0)=\frac{\partial \tilde{T}_{C}(z)}{\partial \alpha} \\
& x(0, t)=\frac{\partial T_{f}(t)}{\partial \alpha}
\end{aligned}
$$


where again functional derivatives imply that for instance:

$$
\frac{a h}{\partial T_{c}} x \equiv \iint_{z^{\prime} t^{\prime}} \frac{\partial\left[h\left(T_{c}\right)\right]}{\partial T_{c}\left(z^{\prime}, t^{\prime}\right)} \frac{d T_{c}\left(z^{\prime}, t^{\prime}\right)}{d \alpha} d z^{\prime} d t^{\prime}
$$

In this case also the integrals are not necessary because $h\left(T_{c}\right)$ is only a function of the local coolant temperature.

In order to simplify the notation, the following new functions are defined:

$$
\begin{aligned}
& S_{\phi}(r, z, t) \equiv \frac{\partial Q}{\partial \alpha}-\frac{\partial\left(\rho c_{\rho}\right)}{\partial \alpha} \frac{\partial T}{\partial t}+\frac{1}{r} \frac{\partial}{\partial r}\left[r \frac{\partial k}{\partial \alpha} \frac{\partial T}{\partial r}\right]
\end{aligned}
$$

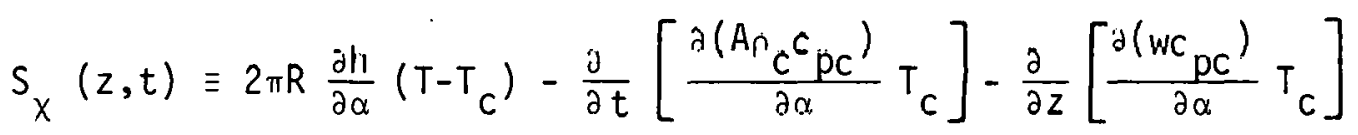

$$
\begin{aligned}
& h^{-} \equiv h-\left.\left(T-T_{c}\right) \frac{\partial h}{\partial T_{C}}\right|_{r=R} \\
& \left(\rho_{c} c_{p c}\right)^{\prime} \equiv \rho_{c} c_{p c}+T \frac{\partial\left(\rho_{c} c_{p c}\right)}{\partial T} \\
& \left(w c_{p c}\right)^{-} \equiv w c_{p c}+T_{c} \frac{\partial\left(w c_{p c}\right)}{\partial T_{c}} \\
& a \equiv-\frac{\partial k}{\partial \alpha} \frac{\partial T}{\partial r}-\left.\frac{\partial h}{\partial \alpha}\left(T-T_{C}\right)\right|_{r=R}
\end{aligned}
$$

Here again the derivatives in Eqs. (23), (24) and (25) are to be interpreted as integral operators in the general case since they are functional derivatives. For this problem, however, the integrals are unnecessary because all the physical properties $\rho, c_{p}, \rho_{c}, c_{p c}$ and $w$ are only functions of local temperatures.

Using these new functions, the Eq. (12) for the fuel region can be rewritten simply as:

$$
\frac{\partial}{\partial t}\left[\rho c_{p} \phi\right]-\frac{1}{r} \frac{\partial}{\partial r}\left[r \frac{\partial(k \phi)}{\partial r}\right]=s_{\phi}
$$


with boundary and initial conditions,

$$
\begin{gathered}
\phi(r, z, 0)=\frac{\partial \tilde{T}(r, z)}{\partial \alpha} \\
\left.\frac{\partial(k \phi)}{\partial r}\right|_{r=0}=0 \\
\frac{\partial(k, \phi)}{\partial r}+\left.h \phi\right|_{r=R}=h^{\prime} x+a
\end{gathered}
$$

Here the central boundary condition on T (i.e. Eq. (4)) was used to get Eq. (29) and because of the local temperature dependence of $k(T)$ it was possible to write:

$$
\frac{\partial k}{\partial T} \phi \frac{\partial T}{\partial r}+k \frac{\partial \phi}{\partial r}=\frac{\partial(k \phi)}{\partial r}
$$

and likewise: $\quad \rho c_{p} \frac{\partial \phi}{\partial t}+\frac{\partial\left(\rho c_{p}\right)}{\partial T} \frac{\partial T}{\partial t} \phi=\frac{\partial}{\partial t}\left[\rho c_{p} \phi\right]$

Similar simplifications can be made in Eq. (17) to get:

$$
\frac{\partial}{\partial t}\left[A\left(\rho_{c} c_{p c}\right) \cdot x\right]+\frac{\partial}{\partial z}\left[\left(w_{p c}\right) \cdot x\right]=2 \pi R\left(h_{\phi}-h \cdot x\right)+S_{x}
$$

with boundary and initial conditions,

$$
\begin{aligned}
& x(z, 0)=\frac{\partial \tilde{T}_{c}(z)}{\partial u} \\
& x(0, t)=\frac{\partial T_{j}(t)}{\partial \alpha}
\end{aligned}
$$

Eqs. (27) and (32) now represent 1 inearized versions of the original heat conduction and convection equations (i.e. Eqs. (1) and (6), henceforth referred to as the "forward" equations). It should be noted that they are no longer non-linear equations since all the physical constants are functions of the temperatures $T$ and $T_{c}$ and are not functions of $\phi$ and $x$. In order to solve such equations (which will not be necessary for this theory but might be for other applications), the forward equations must be solved for a specific problem to determine the functional dependence on $T$ and $T_{C}$ of the constants in the linearized equations. These latter 
equations are therefore coupled to the forward equations in that the former must be solved first to set up the constants for the latter case.

Since the linearized equations only have source terms that depend on $d \alpha$ and their solution is really needed only to evaluate the integral terms in Eq. (10), it is far simpler to define a set of adjoint equations independent of $d \alpha$ to solve this same problem. The adjoint operators for Eqs. (27) and (32) are easily derived and what remains to be done in the derivation is to identify appropriate source terms and boundary and initial conditions for these new equations.

Using the definition of an adjoint operator,

$$
\int_{V} \mu H u d V=\int_{V} u H^{\star} \mu d V
$$

where $p$ and $q$ are arbitrary functions and $H^{*}$ is the adjoint operator of $H$, we can write down equations which are adjoint to Eqs. (27) and (32) after some manipulations as:

$$
-\rho c_{p} \frac{\partial T^{*}}{\partial t}-k \frac{1}{r} \frac{\partial}{\partial r}\left[r \frac{\partial T^{*}}{\partial r}\right]=S_{T}^{*}
$$

and

$$
-A\left(\rho_{c} c_{p c}\right)-\frac{\partial T_{c}^{*}}{\partial t}-\left(w c_{p c}\right)-\frac{\partial T_{c}^{*}}{\partial z}+2 \pi R h-T_{c}^{*}=S_{T c}^{*}
$$

The equation needed to define the source terms and boundary and initial conditions for these equations is derived as follows: (a) multiply Eq. (27) by $T^{\star}$ and Eq. (36) by $T$, subtract the two and integrate over $r, z$, and $t$; (b) multiply Eq. (32) by $T_{c}^{*}$ and Eq. (37) by $T_{c}$, subtract the two and integrate over $z$ and $t$; (c) add the two equations derived in (a) and (b) together. The following equation results from these operations: 
11

$$
\begin{aligned}
& \iiint_{r} \phi S_{T}^{*} 2 \pi r d r d z d t+\iint_{z} x S_{T}^{*} d z d t=\iiint_{r} T^{*} S_{\phi} 2 \pi r d r d z d t+\iint_{z} T_{c}^{*} S_{\chi} d z d t \\
& -\iiint_{r=t} 2 \pi r d r d z d t\left[\frac{\partial}{\partial t}\left[\rho c_{p} \phi T^{\star}\right]+k \phi \frac{1}{r} \frac{\partial}{\partial r}\left[r \frac{\partial T^{*}}{\partial r}\right]-T^{\star} \frac{1}{r} \frac{\partial}{\partial r}\left[r \cdot \frac{\partial(k \phi)}{\partial r}\right]\right] \\
& -\iint_{z t} d z d t\left[\frac{\partial}{\partial t}\left[A\left(\rho_{c} c_{p c}\right)^{-} x T_{c}^{\star}\right]+\frac{\partial}{\partial z}\left[\left(w_{p c}\right)^{-} x T_{c}^{\star}\right]-2 \pi R T_{c}^{*} h_{\phi}\right]
\end{aligned}
$$

Evaluating these integrals where possible (using integration by parts when necessary), the result can be shown to be:

$$
\begin{aligned}
& \iiint_{r} \phi S_{T}^{*} 2 \pi r d r d z d t+\iint_{z} x S_{T C}^{*} d z d t=\iiint_{r} T^{*} S_{\phi} 2 \pi r d r d z d t+\iint_{z} T_{C}^{*} S_{X} d z d t \\
& +\iint_{z} 2 \pi r\left[T^{*} \frac{\partial(k \phi)}{\partial r}-k \phi \frac{\partial T^{*}}{\partial r}\right]_{0}^{R} d z d t+\iint_{z} 2 \pi R T_{C}^{*} h \phi d z d t \\
& -\iint_{r}\left[\begin{array}{ll}
\rho c_{p} & \phi T^{*}
\end{array}\right]_{0}^{t_{f}} 2 \pi r d r d z-\int_{t}\left[\left(w c c_{p c}\right)^{-} X T_{c}^{*}\right]_{0}^{L} d t-\int_{z}\left[A\left(\rho_{c} c p c\right)^{-} X T_{c}^{*}\right]_{0}^{t_{f}} d z
\end{aligned}
$$

Since an adjoint equation which is independent of $d \alpha$ is desired, boundary and final conditions as well as sources must be chosen to eleminate any terms which contain unknown values of $\phi$ or $x$. Using the known boundary and initial conditions for $\phi$ and $x$, the following conditions can be. shown to satisfy the desired criteria:

$$
\begin{aligned}
T_{c}^{*}\left(z, t_{f}\right) & =0 \\
T_{c}^{*}(L, t) & =0 \\
T^{*}\left(r, z, t_{f}\right) & =0 \\
-\left.k \frac{\partial T^{*}}{\partial r}\right|_{r=0} & =0
\end{aligned}
$$




$$
-\left.k \frac{\partial T^{*}}{\partial r}\right|_{r=R}=h\left(T^{*}-T_{C}^{*}\right)
$$

Collecting terms and rewriting Eq. (39) with these new conditions gives:

$$
\begin{aligned}
& \iint_{z} \int_{t} \phi S_{T}^{*} 2 \pi r d r d z d t+\iint_{Z} x\left(S_{T}^{*}-2 \pi R h^{-} T^{*}\right) d z d t=\iint_{r} \int_{Z} T_{t}^{*} S_{\phi} 2 \pi r d r d z d t+\iint_{Z} \int_{t}^{*}{ }^{*} S_{x} d z d t \\
& +\iint_{Z}\left[2 \pi T^{n} T^{\star} a\right]_{r=R} d<d t+\iint_{Z}\left[\rho c_{p} T^{*} \frac{\partial \tilde{T}(r, L)}{\partial \alpha}\right]_{t=0} 2 \pi r d r d z \\
& +\int_{t}\left[\left(w c_{p c}\right)-T_{c}^{*} \frac{\partial T_{i}(t)}{\partial \alpha}\right]_{z=0} d t+\int_{z}\left[A\left(\rho_{c} c_{p c}\right)-T_{c}^{*} \frac{\partial \tilde{T}_{c}(z)}{\partial \alpha}\right]_{t=0} d z
\end{aligned}
$$

Since everything on the right-hand side of Eq. (45) is known from solutions of the forward or adjoint equation, all that remains is to properly choose the source terms. $S_{T}^{\star}$ and $S_{T C}^{*}$. Looking back at Eq. (10), it is clear that the left-hand side of Eq. (45) can be made equivalent to the two integrais in Eq. (10) (remembering that $\phi \equiv d T / d \alpha$ and $x \equiv d{ }_{C} / d \alpha$ ) it the sources for the adjoint equation are chnsen as follows:

$$
\begin{gathered}
S_{T}^{*}=f \\
S_{T C}^{*}=g+2 \pi R h^{\prime} T^{*}
\end{gathered}
$$

With these final definitions, Eq. (10) can be recast in terms of adjoint functions with each term an explicit function of $\alpha$ as: 


$$
\begin{aligned}
& \frac{d P}{d \alpha}=\iint_{r} \int_{t} \frac{\partial f}{\partial \alpha} T 2 \pi r d r d z d t+\iint_{Z} \frac{\partial g}{\partial \alpha} T_{C} d z d t \\
& +\iint_{r} \int_{z} T^{*}\left[\frac{\partial Q}{\partial \alpha}-\frac{\partial\left(\rho c_{p}\right)}{\partial \alpha} \frac{\partial T}{\partial t}+\frac{1}{r} \frac{\partial}{\partial r}\left[r \frac{\partial k}{\partial \alpha} \frac{\partial T}{\partial r}\right]\right] 2 \pi r d r d z d t \\
& -\iint_{z} T_{c}^{*}\left[\frac{\partial}{\partial t}\left[\frac{\partial\left(A \rho_{c} c_{p c}\right)}{\partial \alpha} T_{c}\right]+\frac{\partial}{\partial z}\left[\frac{\partial\left(w c_{p c}\right)}{\partial \alpha} T_{c}\right]\right] d z d t \\
& -\int_{z} \int_{t} 2 \pi R\left[\frac{\partial h}{\partial \alpha}\left(T-T_{C}\right)\left(T^{\star}-T_{C}^{\star}\right)+T^{\star} \frac{\partial k}{\partial \alpha} \frac{\partial T}{\partial r}\right]_{r=R} d z d t \\
& +\int_{t}\left[\left(w c_{p c}\right)-T_{c}^{*} \frac{\partial T_{j}(t)}{\partial \alpha}\right]_{z=0} d t \\
& +\int_{r} \int_{z}\left[\rho c_{p} T^{\star} \frac{\tilde{T}(r, z)}{\partial \alpha}\right]_{t=0} 2 \pi r d r d z+\int_{z}\left[A\left(\rho_{c} c_{p c}\right)-T_{c}^{*} \frac{\partial \tilde{T}_{c}(z)}{\partial \alpha}\right]_{t=0} d z
\end{aligned}
$$

The terms involving $T$ and $T_{c}$ can be evaluated once the forward equations (i.e. Eqs. (1) and (6)) have been solved and the adjoint functions $T^{\star}$ and $T_{c}^{*}$ solve the following set of equations:

(a) in the fuel region,

$$
-\rho C_{p} \frac{\partial T^{\star}}{\partial t}-k \frac{1}{r} \frac{\partial}{\partial r} ;\left[r \frac{\partial T^{\star}}{\partial r}\right]=f
$$

with boundary and final conditions,

$$
\begin{gathered}
T^{\star}\left(r, z, t_{f}\right)=0 \\
-\left.k \frac{\partial T^{*}}{\partial r}\right|_{r=0}=0 \\
-\left.k \frac{\partial T^{*}}{\partial r}\right|_{r=R}=h\left(T^{*}-T_{c}^{*}\right)
\end{gathered}
$$


(b) in the coolant channel,

$$
-A\left(\rho_{c}{ }^{c} p_{c}\right)-\frac{\partial T_{c}^{*}}{\partial t}-\left(w c_{p c}\right)-\frac{\partial T_{c}^{*}}{\partial z}=2 \pi R h-\left(T^{*}-T_{c}^{\star}\right)+g
$$

with boundary and final conditions,

$$
\begin{aligned}
T_{c}^{*}\left(z, t_{f}\right) & =0 \\
T_{c}^{*}(L, t) & =0
\end{aligned}
$$

With the derivation of the adjoint equations completed, the general features of a sensitivity theory for thermal-hydraulics problems begin to become more evident. A single forward and a single adjoint problem solution is all that is needed to evaluate all the derivatives of the response with respect to input data. The adjoint equations required are independent of $d a$ and $d \alpha$ appears explicitly only in the defining expression for $d P / d \alpha$ (i.e. Eq. (48)). The adjoint equations, however, do depend explicitly on the particular response being studied through the source terms in Eqs. (49) and (53).

It is important to also note that the adjoint equations are linear in $T^{*}$ and $T_{C}^{*}$ making them easier to solve than the non-linear forward equations. They are not, however, independent of the forward equations. In order to solve the adjoint problem a particular forward problem solution (called a design point solution) must be available to evaluate the physical constants that go into the adjoint equations. This dependence of the constants on $T$ and $T_{C}$ is a double-edged sword--it linearizes the adjoint equations but also ties the solution of the adjoint equations to a specific design point solution.

Another important point to observe is that the forward and adjoint. equations are very similar in form. Both have differential operators which are very much alike and the canonical form of the equations (i.e. hyperbolic, parabolic, etc.) remains unchanged. The adjoint equations are simply linearized forward equations reversed in time and space with slightly different input data. The same numerical methods (and possibly the same . codes) that solve the forward problem can be used to solve its adjoint. This observation strongly suggests that the method will be applicable 
for more practical problems.

Looking more closely at the nature of the adjoint equations it is also interesting to note that they are final value problems. That is, the adjoint functions are solved by starting at a final time at the spatial position of the response function and moving backwards toward the initial conditions. This fact leads directly to an interpretation of the adjoint solutions as "importance" functions. The adjoint equation solutions starts at the response and traces this value back into the problem phase space along paths which include only those physical phenomena which contribute to the response. The adjoints therefore determine the importance of the physical phenomena for the particular response under investigation. The unfts of these functions are ${ }^{\mathrm{C}} \mathrm{C}$ per watt $/ \mathrm{cm}^{3}$ for a temperature response defined in terms of weighting functions $f$ and $g$ which are unitless. In numerical terms they represent the change in ${ }^{\circ} \mathrm{C}$ of the temperature response for one watt $/ \mathrm{cm}^{3}$ of power put into the system at any time and at any point in space. They are very physical quantities and can clearly be studied in their own right to understand the complex phenomena occurring in any particular thermal-hydraulics problem.

\section{Theory for a Steady-State Problem}

One further development is needed before this illustrative example of a sensitivity theory for thermal-hydraulics problems can be said to be complete. The item remaining deals with the sensitivity terms in Eq. (48) containing the initial conditions for this problem. Typically, the initial conditions are derived from the solution of a suitable steady-state problem. The steady-state solution describes the stable conditions which existed in the reactor system prior to the initiation of any transient event. Insofar as this steady-state problem is the solution to Eqs. and (6) without time derivatives, it also depends on the same input data as the transient problem (i.e. $k, c_{p c}$, w, etc.). To derive expressions for these additional sensitivity terms, one further general aspect of sensitivity theory must first be dealt with--the extension of the theory to cover sensitivity coefficients which require solutions of other sets of equations. 
To see clearly how the theory is extended, the last two terms in Eq. (48) (i.e. those dealing with the derivatives of the initial conditions) can be viewed as the derivative of a new integral response functions $P^{\prime}$, defined as follows:

$\frac{d P^{-}}{d \alpha} \equiv \int_{r} \int_{z}\left[\rho c_{p} T^{\star} \frac{\partial \tilde{T}(r, z)}{\partial \alpha}\right]_{t=0} 2 \pi r d r d z+\int_{z}\left[A\left(\rho_{c} c_{p c}\right)-T_{c}^{*} \frac{\partial \tilde{T}_{c}(z)}{\partial \alpha}\right]_{t=0} d z$

Here $\tilde{T}(r, z)$ and $\tilde{T}_{c}(z)$ are the solutions of steady-state forward problems which can be derived from Eqs. (1) and (6) by ignoring the time derivatives.

In the fuel region, the steady-state equation to be solved is:

$$
\frac{1}{r} \frac{\partial\langle r \tilde{q}\rangle}{\partial r}=\tilde{Q}
$$

where

$$
\tilde{q}(r, z) \equiv-\tilde{k} \frac{\partial \tilde{T}(r, z)}{\partial r}
$$

and

$$
\begin{gathered}
\hat{q}(0, z)=-\left.\hat{k} \frac{\tilde{\nabla T}(r, z)}{\partial r}\right|_{r=0}=0 \\
\tilde{q}(R, z)=-\left.\tilde{k} \frac{\partial \tilde{T}(r, z)}{\partial r}\right|_{r=R}=\tilde{h}\left(\tilde{T}(R, z)-\tilde{T}_{c}(z)\right)
\end{gathered}
$$

In the coolant channel, the corresponding equation is:

$$
\frac{\partial\left(\tilde{w}^{2} H\right)}{\partial z}=2 \pi \tilde{R}^{2}(R, z)
$$

where

$$
\tilde{H}(z)=\tilde{c}_{p c} \tilde{T}_{c}(z)
$$


and

$$
\tilde{T}_{c}(0) \equiv \tilde{T}_{i}
$$

As before, the derivative of Eqs. (57)-(63) with respect to $\alpha$ is taken to derive the linearized equations which $\partial \tilde{T} / \partial \alpha$ and $\partial \tilde{T}_{c} / \partial \alpha$ solve. Defining $\tilde{\phi} \equiv \partial \tilde{T} / \partial \alpha$ and $\tilde{x} \equiv \partial \tilde{T}_{c} / \partial \alpha$, these new equations can be written down by inspection if we refer back to the transient problem equations (i.e. Eqs. (27) and (32)) and ignore all time derivative terms.

In the fuel region we therefore get:

$$
-\frac{1}{r} \frac{\partial}{\partial r}\left[r \frac{\partial}{\partial r}\left(\tilde{k}_{\phi}\right)\right]=\tilde{s}_{\phi}
$$

where

$$
\begin{gathered}
\left.\frac{\partial(\hat{k} \tilde{q})}{\partial r}\right|_{r=0}=0 \\
{\left[\frac{\partial(\hat{k} \dot{\phi})}{\partial r}+\tilde{h} \tilde{\phi}\right]_{r=\mathrm{k}}=\tilde{h}-\tilde{x}+\tilde{a}}
\end{gathered}
$$

and

$$
\begin{gathered}
\tilde{S}_{\phi}=\frac{\partial \tilde{Q}}{\partial \alpha}+\frac{1}{r} \frac{\partial}{\partial r}\left[r \frac{\partial \tilde{k}}{\partial \alpha} \frac{\partial \tilde{T}}{\partial r}\right] \\
\tilde{h}=\tilde{h}-\left(\tilde{T}-\tilde{T}_{c}\right) \frac{\partial \tilde{h}}{\partial \tilde{T}} \\
\tilde{a}=-\frac{\partial \tilde{k}}{\partial \alpha} \frac{\partial \tilde{T}}{\partial r}-\frac{\partial \tilde{h}}{\partial \alpha}\left(\tilde{T}-\tilde{T}_{c}\right)
\end{gathered}
$$

In the coolant we get:

$$
\frac{\partial}{\partial z}[(\tilde{w c} p c) \cdot \tilde{x}]=\dot{2} \pi R\left(\tilde{h}_{\phi}^{\tilde{n}}-\tilde{n} \cdot \tilde{x}\right)+\tilde{S}_{x}
$$


where

$$
\tilde{x}(0)=\frac{\partial \tilde{T}_{i}}{\partial \alpha}
$$

and

$$
\left(\tilde{w c} \tilde{p c}_{c}\right)-\equiv \tilde{w}_{p c}+\tilde{T}_{c} \frac{\partial\left(\tilde{\tilde{w}} \tilde{c}_{p c}\right)}{\partial \tilde{T}_{c}}
$$

Again, by analogy with the transient problem, the integral response function derivative $d P \% / d \alpha$ given by $E q .(56)$ is best evaluated using adjoint functions for the steady-state problem. Looking at the transient adjoint results given in Eqs. (48)-(55), a steady-state expression can be derived by ignoring time derivatives and integrals as:

$$
\begin{aligned}
& \frac{d P^{-}}{d \alpha}=\iint_{r}^{\tilde{T}} \tilde{T}^{\star}\left[\frac{\partial \tilde{Q}}{\partial \alpha}+\frac{1}{r} \frac{\partial}{\partial r}\left[r \frac{\partial \tilde{k}}{\partial \alpha} \frac{\partial \tilde{T}}{\partial r}\right]\right] 2 \pi r d r d z \\
& -\int_{z}^{\tilde{\tau}} \tilde{T}_{c}^{*} \frac{\partial}{\partial z}\left[\frac{\partial\left(\tilde{w}_{p c}\right)}{\partial \alpha} \tilde{T}_{c}\right] d z \\
& -\int_{z} 2 \pi R\left[\frac{\partial \tilde{h}}{\partial \alpha}\left(\tilde{T}-\tilde{T}_{c}\right)\left(\tilde{T}^{\star}-\tilde{T}_{c}^{*}\right)+\tilde{T}^{*} \frac{\partial \tilde{k}}{\partial \alpha} \frac{\partial \tilde{T}}{\partial r}\right]_{r=R} d z \\
& +\left[\left(\tilde{w C}_{p c}\right)-\tilde{T}_{c}^{*} \frac{\partial \tilde{T}_{i}}{\partial \alpha}\right]_{z=0}
\end{aligned}
$$

The source terms for the steady-state case can be obtained by comparing Eqs. (10) and (56) thereby properly defining $f$ and $g$ for this case. The steady-state adjoint equation in the fuel region is then:

$$
-\hat{k}^{\prime} \frac{1}{r} \frac{\partial}{\partial r}\left[r \frac{\partial T^{\star}}{\partial r}\right]=\left[\rho c_{p} T^{*}(r, z, t)\right]_{t=0}
$$


where

$$
\begin{gathered}
-\left.\tilde{k} \frac{\partial T^{*}}{\partial r}\right|_{r=0}=0 \\
-\left.\tilde{k} \frac{\partial T^{*}}{\partial r}\right|_{r=R}=\tilde{h}\left(\tilde{T}^{*}-\tilde{T}_{c}^{*}\right)
\end{gathered}
$$

In the coolant channel we likewise have:

$$
-\left(\tilde{w}_{p c}\right)-\frac{\partial T_{c}^{*}}{\partial z}=2 \pi R \tilde{h}^{-}-\left(T^{*}-T_{c}^{*}\right)+\left[A\left(\rho_{c} c_{p c}\right)-T_{c}^{*}(z, t)\right]_{t=0}
$$

where

$$
T_{c}^{n *}(L)=0
$$

The final expression for $\mathrm{dP} / \mathrm{d} \alpha$ (i.e. Eq. (73)) can now be used to replace the last two terms in Eq. (48). Because the procedure for solving the transient problem in this case also involves the solution of a steadystate problem, the sensitivity coefficients for most of the input parameters have two terms: one describing the effects of changes in $\alpha$ on the steadystate solution (i.e. the initial conditions for the transient) and a second describing the effect of these changes on the transient solution.

It is interesting to note that the procedures for solving the adjoint equations are now completely the opposite of those which would be used in a forward problem. The adjoint problem solution is started at a final time, with the response function as the source and the transient equations are solved first moving backwards in time. When the initial time is reached the transient solution is used in Eqs. (74) and (77) as the source for a steady-state problem which is solved next. This reversal of procedures is typical of all adjoint problems and is consistent with the physical interpretation of the adjoint solutions as "importance" functions for a particular final response.

The method just used to develop adjoint equations for the terms in $\mathrm{dP} / \mathrm{d} \alpha$ derived from the solution of a steady-state problem is also the general approach needed to expand any of the derivative terms in Eqs. (48) or (73). For instance, the heat transfer coefficient is generally 
a complicated function of temperature and flow conditions in the coolant stream and is described by empirical correlations. In many cases, these correlations require the solutions to momentum balance equations (or simplified approximations of them) to understand the velocity profiles in the coolant channel. These auxiliary equations can also be cast in adjoint form and coupled with the main heat balance adjoint equations if sensitivity questions concerning the heat transfer coefficient correlation functions are to be answered.

\section{Solution of a Sample Sensitivity Problem}

To make the results of the derivations in the preceding sections more understandable in a practical sense, a sample steady-state, therma 1hydraulics problem for the $\mathrm{Cl}$ inch River Breeder Reactor (CRBR) was devised. Although a full transient treatment could have been pursued, it is more instructive to look in depth at the results of the simpler steady-state problem. The sensitivity derivatives for this case (see Eq. (73)) are very similar in form to those for the transient problem (see Eq. (48)) if the time functions are ignored. It is also easier to show the behavior of the complete solution to the adjoint problem and derive a physical feeling for these functions in this more restrictive case.

A description of a typical CRBR fuel pin and coolant channel is given in Table $I$, along with some initialization data for the steady-state problem. The physical input data for $\tilde{k}, \tilde{c}_{p c}$, and $\tilde{h}$ were all taken to be functions of temperature ${ }^{2}$, and are given in Fig. 2 and Table II. A small non-linear, ordinary differential equation solution code was written to solve both the forward and adjoint heat balance equations (Eqs. (57) and (61) and tqs. (14) and (77), respectively). The source term in the fuel for the forward problem was taken to be a cosine distribution axially and flat radially. For the adjoint equations, however, the sources were not derived from the initial conditions of a transient adjoint equation. The response for the steady-state problem was taken to be of the same form as the general response function given in Eq. (9) with time behavior ignored. Several typical responses such as: coolant outlet temperature, peak clad temperature, and peak and center-line average fuel temperature, were then defined by 


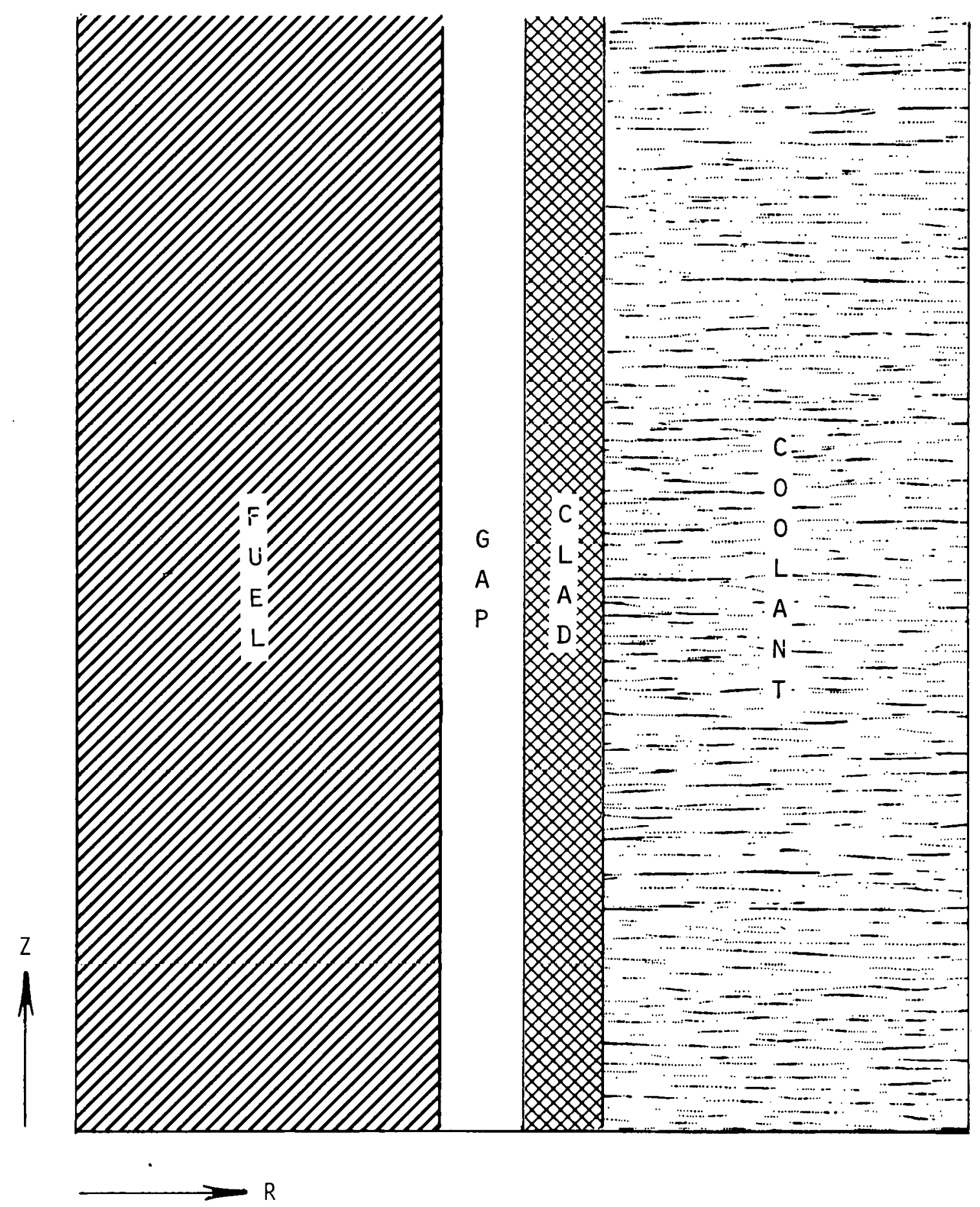

Fig. 1. Typical Geometric Configuration of a Fuel-Coolant Channel. 


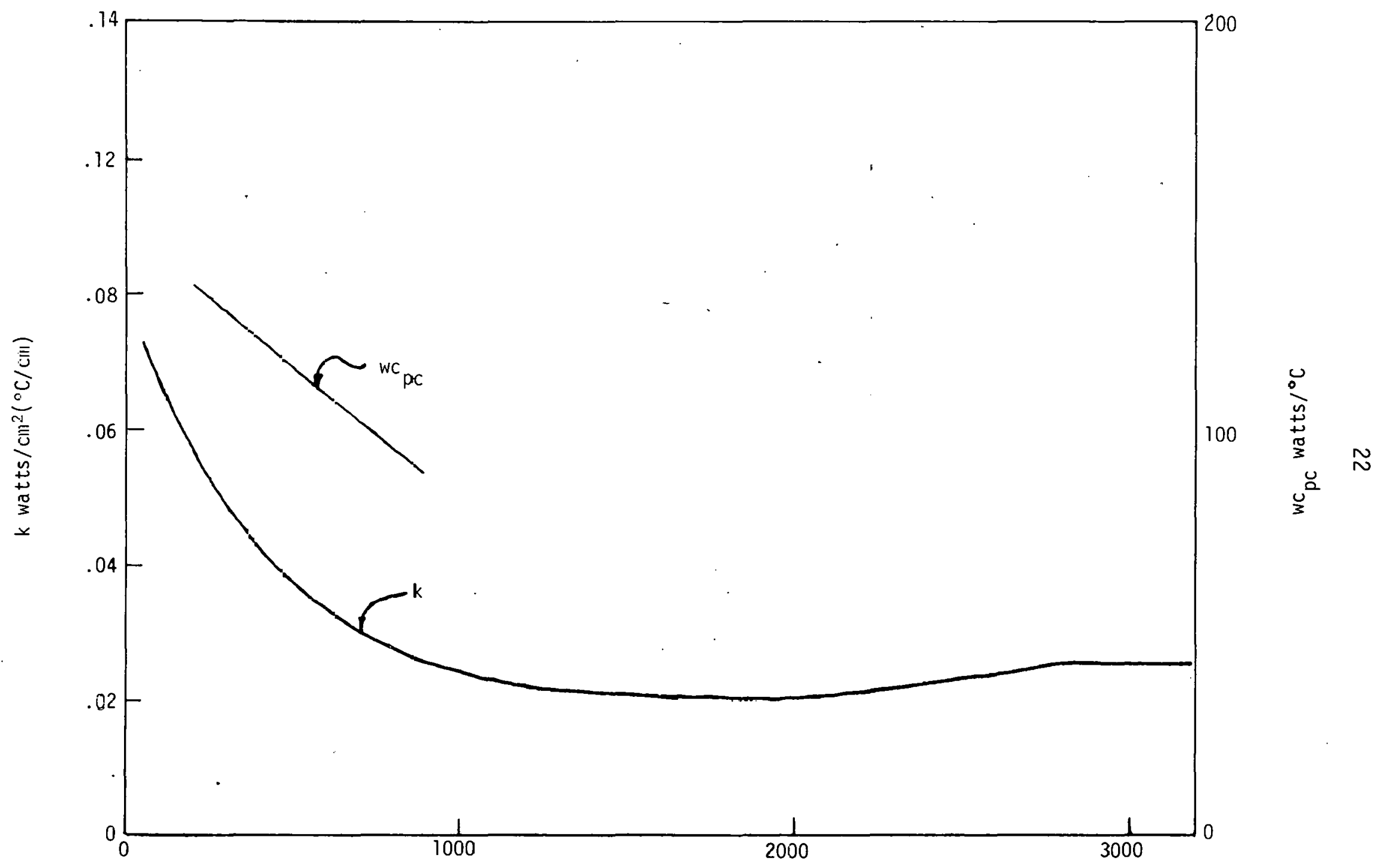

Fig. 2. Physical Data for CRBR Problem as a Function of Temperature. 
Table I. CRBR Sample Problem Input Specifications

Fuel Pin (mixed Pu-U oxide) Outer Radius

Gap (helium and fission products) Outer Radius

Clad (stainless steel) Outer Radius (R)

Coolant Channe] (sodium) Cross Sectional Area (A)

Coolant Channel Length

Fuel Pin Power ( $(\tilde{Q})$

Power Distribution

Coolant Flow Rate $(\tilde{w})$

Inlet Coolant Temperature $\left(\tilde{T}_{j}\right)$
$0.2457 \mathrm{~cm}$

$0.254 \mathrm{~cm}$

$0.2921 \mathrm{~cm}$

$0.359 \mathrm{~cm}^{2}$

$162.6 \mathrm{~cm}$

$2.427 \times 10^{4}$ watts

Flat Fadially and Cosine Axially

$112 \mathrm{gm} / \mathrm{sec}$

$388^{\circ} \mathrm{C}$ 
Table II. Physical Data for CRBR Sample Problem

$\begin{array}{ll}\text { Clad Thermal Conductivity } & 0.21 \text { watt } / \mathrm{cm}^{2}\left({ }^{\circ} \mathrm{C} / \mathrm{cm}\right) \\ \text { Gap Equivalent. Thermal Conductivity } & 0.00 \mathrm{c} \text { watt } / \mathrm{cm}^{2}\left({ }^{\circ} \mathrm{C} / \mathrm{cm}\right)\end{array}$

Heat Transfer Coefficient Correlation:

$$
\tilde{h}=(7.0+0.025 \mathrm{Pe} \cdot 8) \frac{\tilde{k}_{c}}{D} \text { watt } / \mathrm{cm}^{2}{ }^{\mathrm{c}} \mathrm{C}
$$

where

$$
\begin{aligned}
& \mathrm{Pe}=\frac{\tilde{w C}_{p c}^{2} D}{\tilde{k}_{c} A} \\
& \tilde{k}_{c}=0.66 \text { watt } / \mathrm{cm}^{2}\left({ }^{\circ} \mathrm{C} / \mathrm{cm}\right) \\
& ᄃ=4 A / 2 \pi R
\end{aligned}
$$


suitable choices of $f(r, z)$ and $g(z)$. thus providing appropriate adjoint sources.

The results of a run with the typical CRBR data presented are given in Fig. 3. Here the steady-state temperature profile at the center of each radial and axial node is plotted as a function of space in both the fuel and coolant regions. The fuel temperature has the same general cosine shape axially as the nuclear heat source and peaks near the center (both axially and radially) of the pin. The coolant temperature on the other hand increases monotonically in the axial direction as more heat enters from the fuel rod. The clad temperature, therefore, peaks somewhere near the end of the coolant. channel.

To investigate the sensitivity of the steady-state CRBR temperature profile to the physical input data used, several figures of merit for the temperature distribution were chosen as responses for study. The three most interesting were: 1) peak fuel temperature, 2) peak clad temperature and 3 ) average (axial) central fuel temperature. Adjoint equations for each one of these responses were solved and the results were used for a complete sensitivity and uncertainty analysis of all the physical input data. The behavior of the adjoint functions for these three cases is shown in Figs. 4-6. Here the adjoints with units of ${ }^{\circ} \mathrm{C}$ per watt $/ \mathrm{cm}^{3}$ represent the differential change in the temperature response in ${ }^{\circ} \mathrm{C}$ for a differential change in the volumetric power source in watts $/ \mathrm{cm}^{3}$ made at the center of each axial or radial node plotted.

Close inspection of these adjoint functions reveals a weal th of physical information about the heat conduction and convection processes in this sample problem. For instance, in the plot of the adjoint for a peak fuel temperature response (see Fig. 4), the "importance" of a differential unit of power put into the system at any axial level is negligible unless it is put at the level where the peak temperature occurs. This effect is primarily the result of the absence of any axial heat conduction in the fuel. The only way power at axial positions other than the one where the fuel temperature peaks can influence the peak temperature is by radial 
ORNL-DWG 78-3632

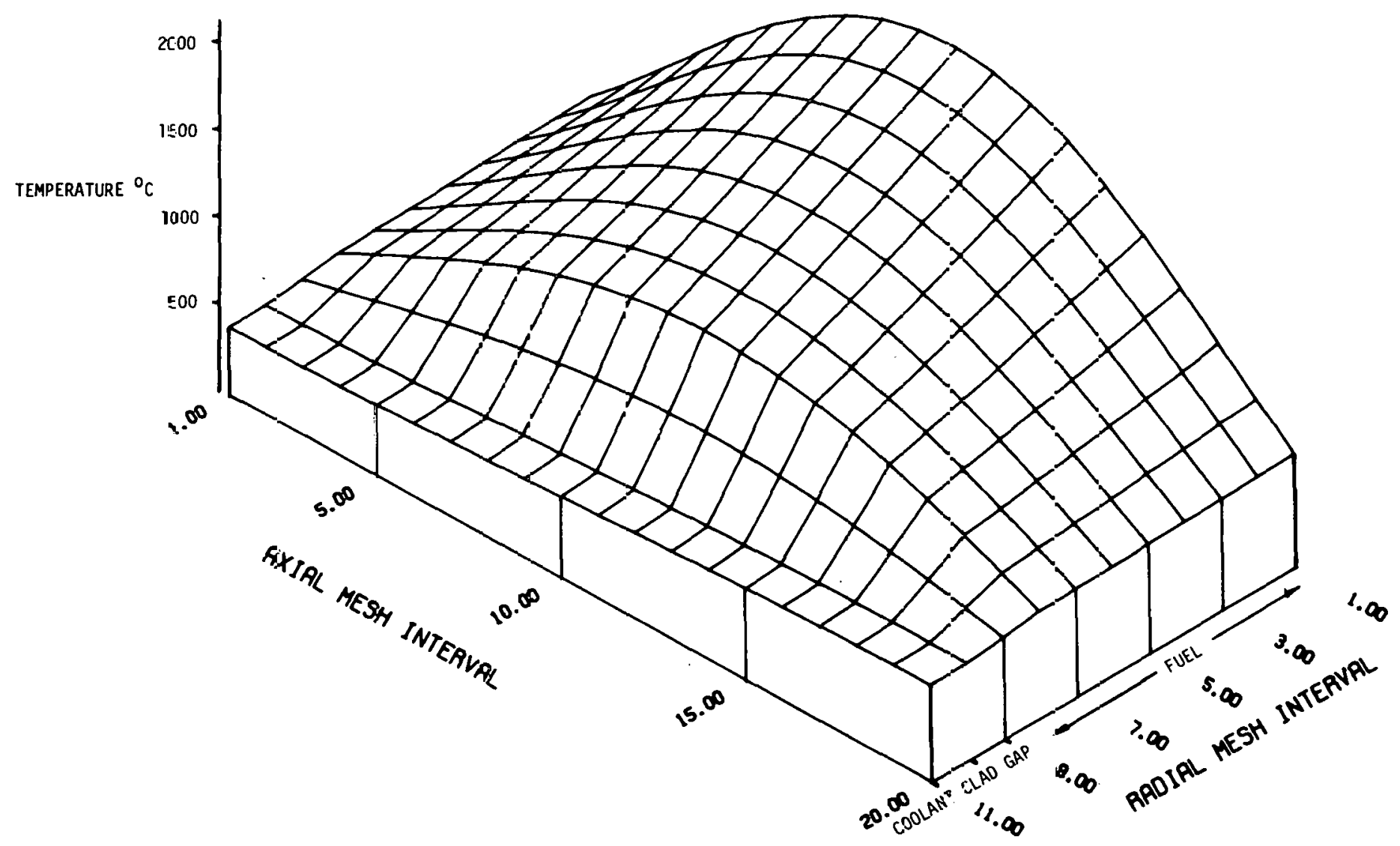

Fig. 3. Steady-State Temperature Profile in CRBR Channel. 
ORNL-DWG 78-3633R

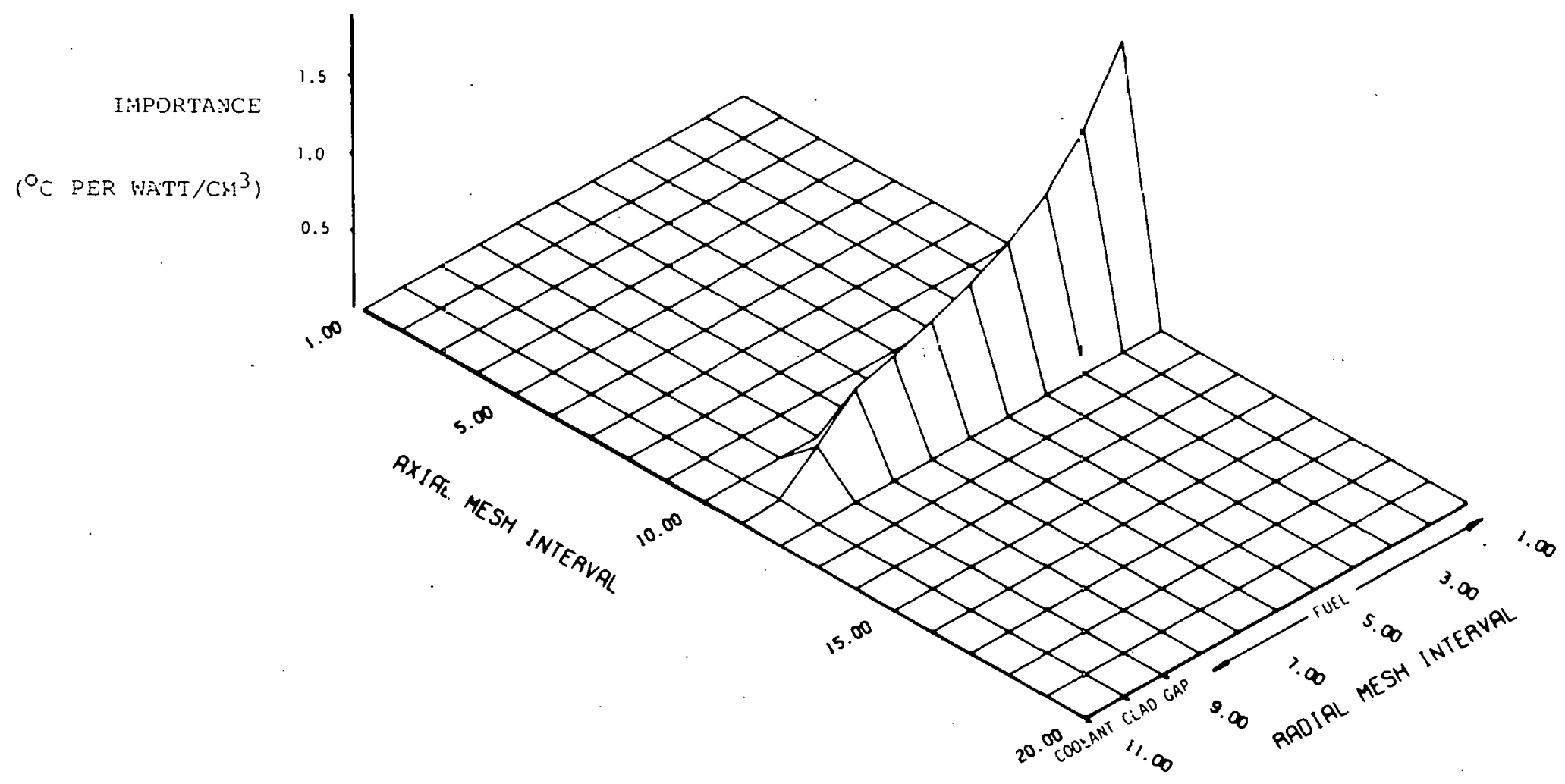

Fig. 4. Adjoint Temperature Profile for Peak Fuel Temperature Response in CF.BR Channel. 
ORIL-DWG 78-3635R

(OC PER WATT/CN 3 )

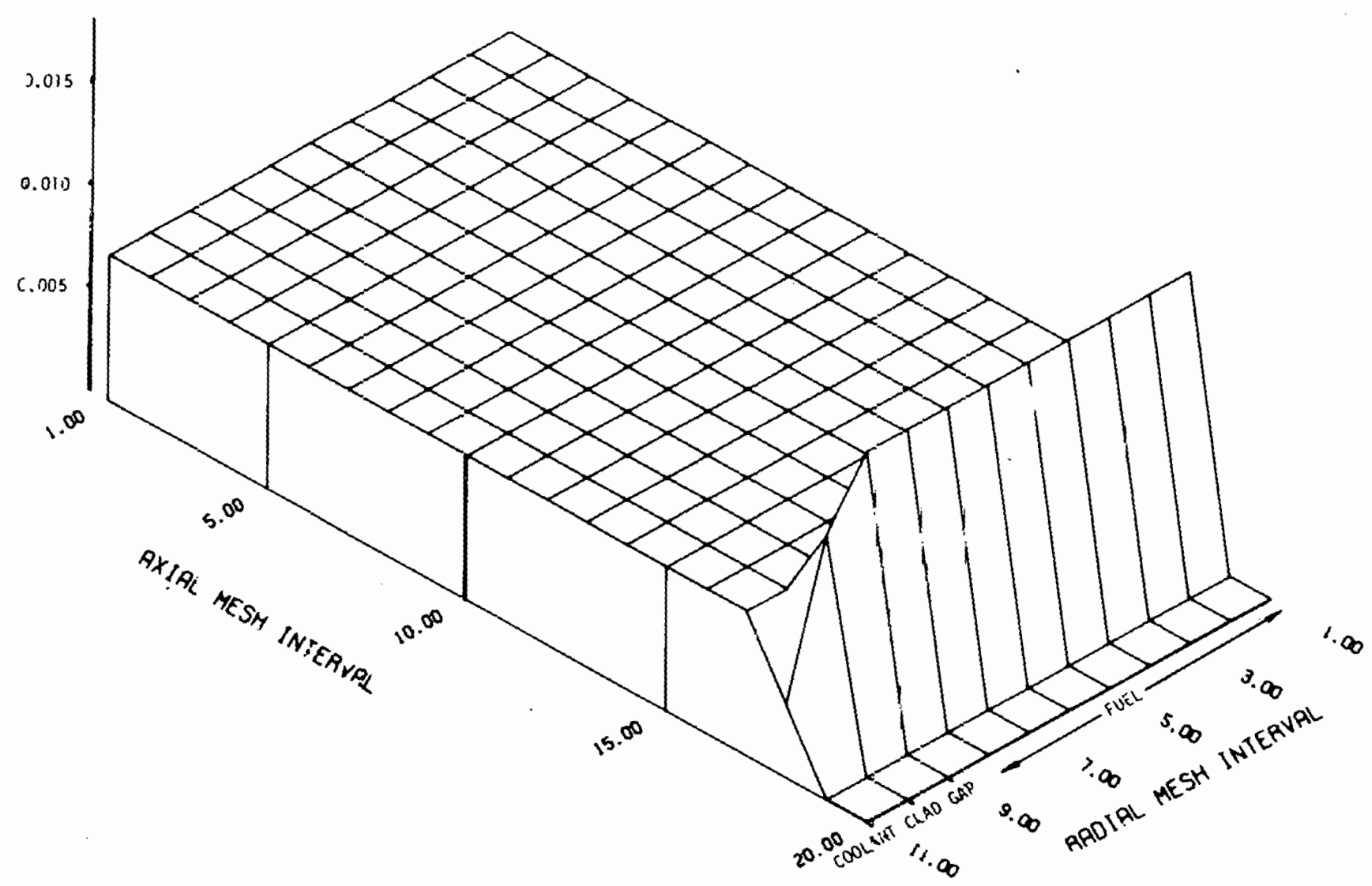

Fig. 5. Adjoint Temperature Profile for Peak Clad Temperature Response in CRER Channel. 


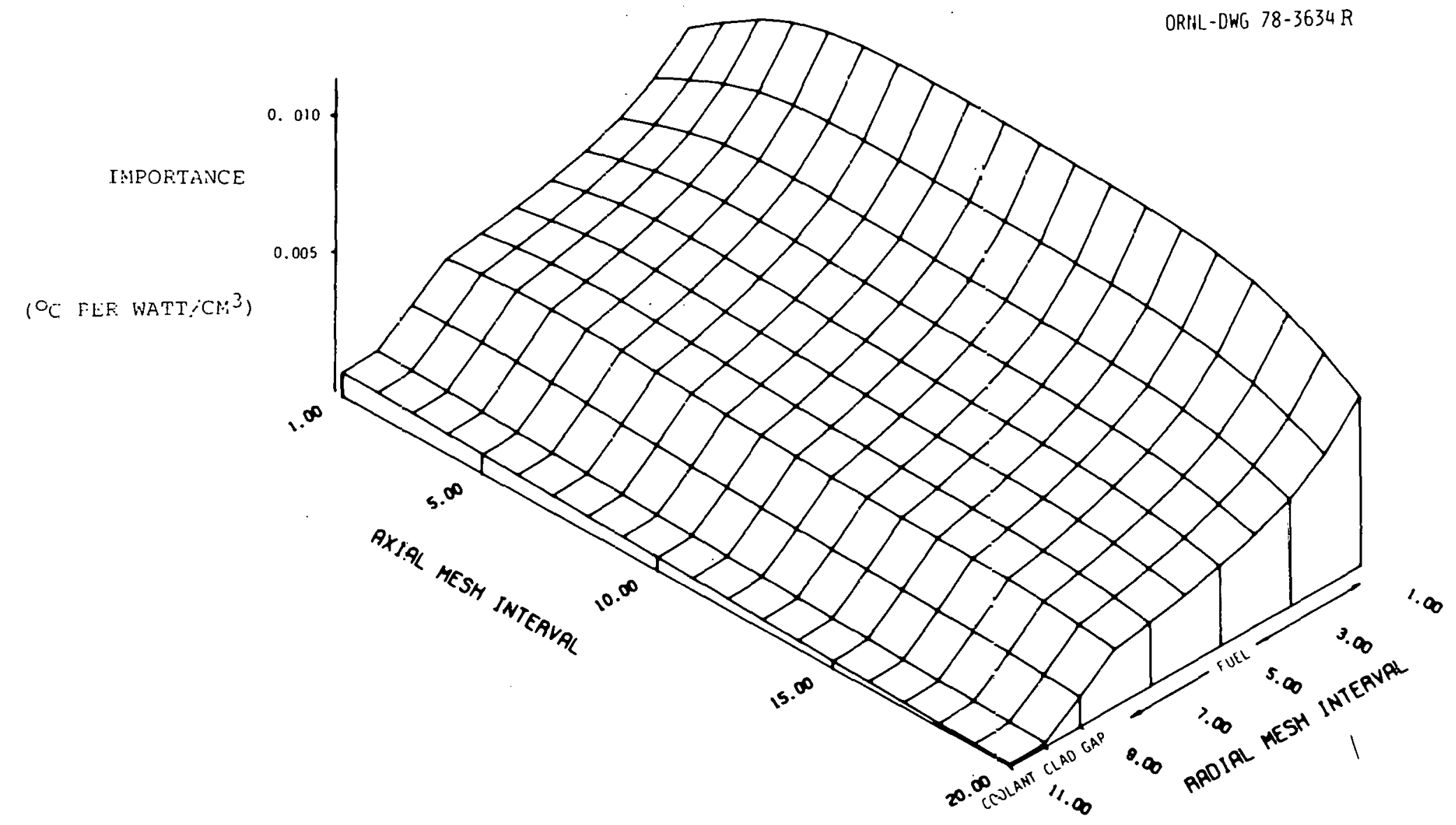

Fig. 6. Adjoint Temperature Profile for Average FLel Centerline Temperature Response in CRBR Channel. 
conduction followed by axial convection in the coolant. This mode of heat transfer produces very small temperature increases in the coolant due to the high mass flow rate and therefore only these very small temperature increases are passed from the coolant to the center of the fuel.

Another example of the usefulness of the adjoint functions is obtained from analysis of Fig. 5. Here the "importance" of a differential unit of power is zero for all axial positions downstream from the peak position (the peak occurs at axial interval 18). Again, because there is no axial conduction in the fuel, any power source downstream from the peak clad temperature can only influence the clad temperature through coolant convection. Since the coolant flows in only one direction, a downstream power source has no influence on the clad or any other region temperature. These comments also apply to the results given in Fig. 4 al though the scale in this figure makes it more difficult to see.

The fact that all upstream differential power sources have equal importance is a result of the fact that at steady-state any power put into the fuel will eventually be transferred to the coolant. This power will produce about the same temperature rise in the coolant across an axial mesh interval if ${ } c_{p c}$ is fairly constant, as it was for this case. The higher importance of a power source at the axial position of the peak clad temperature (i.e., axial interval 18) is due to the fact that both conduction and convection processes in this axial interval can effect the clad temperature as opposed to convection alone at all upstream positions.

It is also interesting to observe that the absolute magnitude of the importance at the peak axial position (about $0.015{ }^{\circ} \mathrm{C}$ per watt $/ \mathrm{cm}^{3}$ ) for this response is about two orders of magnitude lower than the highest importance value in Fig. 4. This is the result of two effects. First, the peak clad temperature $\left(561^{\circ} \mathrm{C}\right)$ is about a factor of four lower than the peak fuel temperature $\left(1940^{\circ} \mathrm{C}\right)$ and second, the number of axial levels that can influence the peak clad temperature is about 20 compared to effectively only one for the peak fuel temperature. This latter condition has the effect of spreading out the total importance and therefore 
lowering its absolute value at any one axial or radial position.

Continuing on to the next phase of the study, the forward and adjoint solutions were used to evaluate the expression for $d P / d \alpha$ ( $E q$. (73)) and a full sensitivity analysis was performed for the CRBR problem. A small code was written to perform the integrals needed and several responses of interest were studied. Some of the results obtained are summarized in Table III. It should be noted that the column labeled sensitivity contains the evaluated derivatives $\mathrm{dP} / \mathrm{d} \alpha$ multiplied by $\alpha / P$ to form a logarithmic derivative $\frac{d P / P}{d \alpha / \alpha}$ which is commonly referred to as the sensitivity of $P$ to $\alpha$. In addition, it should be clear that $\alpha$ was used only symbolically in the derivations to represent any of the data thal were betigg siudled. Ihe sensitivity results reported for each input parameter were obtained by defining $\alpha$ to be a scale factor for that particular parameter, thereby reducing the expression for $d P / d \alpha$ to only the one or two terms involving that parameter. For instance, the sensitivity of peak fuel temperature to the nuclear heat source, $\tilde{Q}$, would involve defining $\alpha \equiv \tilde{Q}_{0}$ (a scale factor for the power) in Eq. (73) and setting al1 terms except the one for $\partial \tilde{Q} / \partial \alpha$ equal to zero. The sensitivities thus obtained are known as "integral sensitivities" and can be thought of as the percent change (positive or negative) in the response for a $1 \%$ increase in the scale (i.e. magnitude) of the input parameter. In other applications, $\alpha$ can be allowed to be a function (i.e. the spatial behavior of $\tilde{Q}(r, z))$ and a "sensitivity profile" can be defined as a spatial density function using functional derivative notation.

Looking at the results presented in Table $1 \mathrm{II}$, it is easy to see how the particular behavior of each of the adjoint functions shown in Figs. 4-6 gives rise to the reported sensitivities of each of the individual input parameters. The parameters with the largest sensitivities in absolute magnitude are those which affect the temperature profile in regions of high importance for this problem and those that have small sensitivities only affect unimportant regions. Since the nuclear heat source directly affects the heat balance in the fuel region, both the peak clad and peak fuel temperatures are very sensitive to it. On the other hand, the heat transfer coefficient and clad thermal conductivity have very little effect 
Table III. Typicai Sensitivity Results for SRBR Test Problem

Response

Peak Clad Temperature

$\left(561^{\circ} \mathrm{C}\right)$

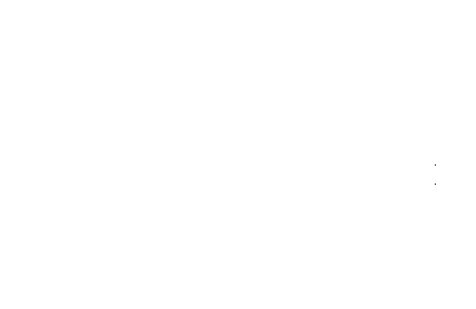

Peak Fuel Temperature $\left(1940^{\circ} \mathrm{C}\right)$
Parameter

Coolant Inlet Temperature

Heat Source

Coolant wC $p$

Clad Thermal Conductivity

Coolant Heat Transfer Co fficient

Fuel and Gap Conductivity

He:at Source

Fuel Thermal Conductivity

Gëp Thermal Conductivity

Coolant Inlet Temrerature

Coolant wc $p c$

Coolant Heat Transfer Caefficient
Parameter $\star *$

Sensitivity ${ }^{*}$ Uncertainty $\%$ Uncertainty

$\begin{array}{lr}.69 & 10 \\ .31 & 5 \\ -.29 & 10 \\ -.009 & 20 \\ -.006 & 30 \\ - & \\ .89 & 5 \\ -.45 & 15 \\ -.37 & 30 \\ .23 & 10 \\ -.06 & 10 \\ -.005 & 30\end{array}$

Response ${ }^{\star \star \star}$

Uncertainty $(\%)$
7.7

10

20

30

14

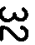

* Can be interpreted as the per cent crarige in the response function for a $1 \%$ increase in the system parameter.

$\star \star$ Estimated standard deviation for parameter.

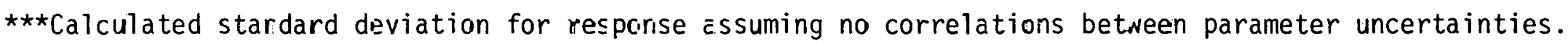


on these two responses because they have a relatively minor effect on the steady-state temperatures in the fuel rod. In general, a dramatic difference in sensitivity from one case to another (i.e. for fuel and gap conductivity) is a reflection of large differences in the value of the adjoint function.

For this case, the most dramatic effect present appears to be the sensitivity of both the peak fuel and peak clad temperature responses to the thermal conductivity in the fuel-clad gap region (treated in this case with an equivalent gap conductance). Since there is such a large temperature change across the gap (about $500^{\circ} \mathrm{C}$; see $\mathrm{Fig} .3$ ), it is not surprising that the peak fuel temperature is very sensitive to the gap conductivity. Even though the gap is very sma11, the large temperature drop that occurs crossing it is almost $30 \%$ of the change over the whole fuel rod. This results in a gap sensitivity which is close to $30 \%$ of the heat source sensitivity for this response. On the other hand, the gap conductivity has little effect at steady-state on the amount of heat getting out of the fuel into the coolant (the total amount generated will always be be conducted into the coolant) and therefore has little effect on the peak clad temperature. This response is affected mostly by clad coolant properties or dirert. changes in the heat source itself.

In addition to their usefulness in the foregoing discussion of relative importance of data and heat transfer mechanisms, sensitivity derivatives can also be used to formulate a first order perturbation theory. This theory is based on establishing an analytic relationship between the response and the input data. The simplest form for this relationship is derived from a first order Taylor series expansion of the response about a particular calculated design point, symbolized by the vector of all input data at a particular point $\bar{\alpha}_{0}$. This relationship, written out to second order accuracy, is:

$$
P\left(\bar{\alpha}_{0}+\overline{\delta \alpha}\right) \cong P\left(\bar{\alpha}_{0}\right)+\int_{v}\left[\frac{d P}{d \bar{\alpha}(v)}\right]_{\alpha=\alpha_{0}} \cdot \overline{\delta \alpha}(v) d v
$$


where $[d P / d \bar{\alpha}(v)]_{\alpha=\alpha_{0}}$ is the vector of derivatives for each separate $\alpha$ of the input data field evaluated at $\bar{\alpha}=\bar{\alpha}_{0} ; \overline{\delta x}(v)$ is the vector of finite changes in the input data as a function of the problem phase space (i.e. space and time $) ; P\left(\bar{\alpha}_{0}\right)$ is the response evaluated at $\bar{\alpha}_{0}$; and $P\left(\bar{\alpha}_{0}+\overline{\delta \alpha}_{\alpha}\right.$ is the response evaluated with the altered input data set.

Rearranging, this expression can be cast into a linear perturbation theory form as follows:

$$
\frac{\delta P}{P} \equiv \frac{P\left(\bar{\alpha}_{0}+\overline{\delta \alpha}\right)-P\left(\bar{\alpha}_{0}\right)}{P\left(\bar{\alpha}_{0}\right)}=\int_{v} \bar{s}_{\alpha} \cdot \frac{\overline{\delta \alpha}}{\alpha} d v
$$

where $\bar{s}_{\alpha}$ is the vector of sensitivity coeffictents each element of which has the form $\mathrm{dP} / \mathrm{P} / \mathrm{d} \alpha_{i} / \alpha_{i}$ and $(\overline{\delta \alpha / \alpha})$ is the fractional perturbation vector with elements $\left(\delta \alpha_{j} / \alpha_{i}\right)$ as a ruiction of the problam phase space. In both Eqs. (79) and (80) the derivatives and sensitivities were taken to be in functional derivative form for the sake of generality and therefore were integrated over all phase space $v$.

The usefulness of Eq. (80) as a perturbation theory expression has already been pointed out in Table III where the sensitivities were interpreted as a percent change in $P$ for a percent increase in $\alpha$. In this case the fractional change vector has only one element which is a constant (i.e. 0.01) for the particular $\alpha$ being looked at and the sensitivity coefficient vector is the total sensitivity for that particular $\alpha$ (1.e. $\left.\int_{\alpha i} d v\right)$. For other applications it is possible to estimate the change in the response caused by any arbitrary change in the input data field using Eq. (80). The limitation of this formula is the range within which $P$ is a linear function of the input data (i.e. close to the calculated design point at which $P\left(\bar{\alpha}_{0}\right)$ and the sensitivities are evaluated).

With these comments in mind, it is possible to consider the statistical nature of the inpul dald base as forming an ensemble of finite (and hopefully small) perturbations of the data about $\bar{\alpha}_{0}$. Since most of the input data are experimentally derived, information about the standard deviation of the distribution function of $\bar{\alpha}$ about its nominal value, $\bar{\alpha}_{0}$, and correlations between the different input data can be put into Eq. (80) to formulate a first order uncertainty theory. This is done by squaring 
Eq. (80) and taking its expectation value over the correlated ensemble of statistical input data variations, to get:

$$
\sigma_{\mathrm{p}}^{2}=\mathrm{s}^{-\operatorname{tr}} \overline{\mathrm{s}}
$$

where, $\sigma_{p}$ is the standard deviation in the response; $C$ is the correlation matrix with elements along the diagonal representing the standard deviations in the input data and off-diagonal elements representing the correlations between the input data; and $\bar{s}$ and $\bar{s}$ tr are the total sensitivity vector and its transpose. For the simple case of uncorrelated input data, C will be a diagonal matrix of standard deviations.

To illustrate the use of Eq. (81), a very crude estimate was made of the uncertainties in the input data for the CRBR problem, under the assumption of no data correlations. The estimated standard deviations of some of the input parameters are given in Table III along with the standard deviation in the responses resulting from these uncertainties.

From these results it is clear that the major data uncertainty contributing to the $7.7 \%$ uncertainty in the peak clad temperature response is the $10 \%$ uncertainty in the coolant inlet temperature. The fact that 20-30\% uncertainties exist in the conduction and convection properties of the fuel and coolant are of little concern because of their low sensitivities. On the other hand, for the $14 \%$ uncertainty in the central fuel temperature almost nothing but the $30 \%$ uncertainty in the gap conductivity and the $15 \%$ uncertainty in the fuel conductivity is of much concern. It should be noted that these results are expected to be strongly influenced by the nature of the correlations which exist between the data. A more refined uncertainty analysis would require careful evaluations of the uncertainties of all data of significant importance in this problem. Despite the crudeness of the current analysis, these results underscore the need to take both the uncertainty and sensitivity results into account in analyzing the uncertainty in any particular response. Since sensitivities are in general problem and response dependent care must be taken in using this information properly. 


\section{Summary and Conclusions}

The extension of reactor sensitivity theory to non-linear thermalhydraulics problems was successfully outlined in this paper. These developments provide the framework for a powerful new approach to analyzing both the physics and safety aspects of LWR and FBR designs. The theory has several strong points which were highlighted in reactor sensitivity applications. First, for a large input data base, the use of adjoint functions to develop a sensitivity theory allows all the data to be analyzed using only a single forward and adjoint run for each system response function being studied. This tremendous savings in computer time compared with currently used response surface methods is a strong incentive to apply the adjoint approach whenever possible. Second, the adjoint functions offer strong physical insight into the processes which occur in any particular problem, making a potentially black-box code somewhat more understandable. Last, the same usefulness of sensitivity coefficients in formulating a 1 inear perturbation theory and a theory for uncertainty analysis is also present.

For more general applications several other benefits of the method are also apparent. For instance, the adjoint equations for non-linear forward problems are linear, making them easier to solve. In addition, the form of these adjoint equations and their boundary and final conditions strongly resemble the forward equations. This makes it conceptualily possible to use the same computer codes and numerical methods to solve both the forward and adjoint equations. A test of this theory should now be possible within the framework of an existing thermal-hydrautics or safety code.

While the benefits of reactor sensitivity theory appear for the most part to apply to thermal-hydráulics problems, some additional complications must be overcome in this new application. The least worrisome of these, although it still must be dealt with, is the tendency of the solution of non-linear equations to behave in a more non-linear fashion as a function of input parameter variation. This factor makes it more difficult to apply a linear theory in perturbation applications. Here, however, some experience with non-linear reactor physics problems offers 
the possibility of using multiple forward and adjoint runs and high order interpolation schemes to map out non-linear response surfaces. The derivatives around a single design point available from a single adjoint run actually make it possible to more efficiently choose the data for the new calculations (i.e. a steepest descent approach using the derivatives to form a multi-phase space gradient).

More of a problem is the fact that the adjoint problem requires the solution of the forward problem to determine its input data base. This means that in addition to saving the forward problem solution at all points in phase space, the behavior of all physical data which depend on this solution (i.e. all non-linear data) must also be saved as a function of phase space. This means that essentially the whole forward solution path including all model changes for the data must be saved for an adjoint calculation. At best this will be a large bookkeeping problem and for applications with some large computer codes it might well nullify the inherent advantages of the adjoint approach.

A further problem is the inherent diversity of physical constants needed in a thermal-hydraulics or safety calculation. This results in a large number of terms of differing form in the expression for the sensitivity coefficient. Compared to the expressions which arise in reactor physics applications, the thermal-hydraulics problem is an order of magnitude larger. The sensitivity code that utilizes the results of forward and adjoint equations will therefore have to be larger. On the relative scale of these larger thermal-hydraulics and safety codes, the adjoint approach is still cost effective and this sensitivity code scale-up only poses problems of a theoretical nature. In practice there should be little. difficulty with this coding problem.

On balance, it appears that there will be significant practical thermal-hydraulics and safety problems for which adjoint sensitivity theory can be used profitably. In a future paper an easier approach to deriving the adjoint equations for these more practical cases will be explored. An effort will be made to use more symbolic notations and illustrate the approach for the case of adding point kinetics and momentum balance equations to the heat balance equations. The solution to this expanded problem 
will more clearly delineate those areas in which the adjoint theory will or will not be successful. In the meantime practical applications with specific computer codes will be undertaken to test the theory on a caseby-case basis. 


\section{REFERENCES}

1. K. V. Moore and W. H. Rettig, "RELAP4--A Computer Program for Transient Therma 1-Hydraul ic Analys is," ANCR-1127, Aerojet-Nuclear Corp. (December 1973).

2. F. E. Dunn, et al, "The SAS3A LMFBR Accident Analys is Computer Code," ANL/RAS 75-17, Argonne National Laboratory (1975).

3. A. E. Waltar, et al, "MELT-III: A Neutronics, Thermal-Hydraulics, Computer Program for Fast Reactor Safety Analys is," HEDL-TME 74-47, Hanford Engineering Development Laboratory (1974).

4. R. H. Myers, Response Surface Methodology, Allyn and Bacon, Inc., Boston (1971).

5. N. D. Cox, "Comparison of Two Uncertainty Analysis Methods," Nucl. Sci. Eng. 64, 258 (1977).

6. J. K. Vaurio and C. Mueller, "A Probabalistic/Deterministic Procedure for Analyzing LMFBR Core Disruptive Accidents," Proc. Int. Mtg. Fast Reactor Safety and Related Physics, Chicago (1976).

7. M. D. McKay, W. J. Conover and D. E. Whiteman, "Report on the Application of Statistical Techniques to the Analys is of Computer Codes," LA-NUREG-6526-MS, Los Alamos Scientific Laboratory (1976).

8. C. Mueller, et al, "SACO-1: A Fast-Running LMFBR Accident Analysis Code," ANL/RAS 77-50, Argonne National Laboratory (1977).

9. M. E. Wells and C. B. Davis, "Quarterly Technical Report on Water Reactor Safety Programs," July-September 1975, ANCR-1296, Aerojet Nuclear Corp. (1976).

10. E. M. Oblow, "Sensitivity Theory from a Differential Viewpoint," Nucl. Sci. Eng. 59, 187 (1976); see also, E. M. Oblow, "Reactor Cross Section Sensitivity Studies Using Transport Theory," ORNL/TM-4437 (April 1974).

11. G. C. Pomraning, J. Math, Phys., 8,149 (1967).

12. L. N. Usachev, "Perturbation Theory for the Breeding Ratio and for Other Number Ratios Pertaining to Various Reactor Processes," J. Nucl. Energy, Pts. A/B 18, 571 (1964).

13. A. Gandini, "A Generalized Perturbation Method for Bilinear Functionals of the Real and Adjoint Neutron Fluxes," J. Nucl. Energy 21, 755 (1967). 
14. W. M. Stacey, Jr., Variational Methods in Nuclear Reactor Physics, Academic Press, N.Y. (1974).

15. D. E. Bartine, E. M. Oblow, and F. R. Mynatt, "Radiation Transport Cross Section Sensitivity Analysis - A General Approach Illustrated for a Thermonuclear Source in Air," Nucl. Sci. Eng. 55, 147 (1974).

16. E. Greenspan, "Developments in Perturbation Theory," Advances in Nuclear Science and Technology, $\underline{9}$ (1977).

17. S. A. W. Gerst1, D. J. Dudziak, and D. W. Muir, "Cross Section Sensitivity and Uncertainty Analys is with Application to a Fusion Reactor," Nucl. Sci. Eng. 62, 137 (1977).

18. D. R. Harris, "Sensitivity of Nuclear Fuel Cycle Costs to Uncertainties in Nuclear Data and Methods, "Doctoràl Thests, Rennselaer PulyLechnic Institute, Troy, N.Y. (October 1976).

19. M. L. Williams and C. R. Weisbin, "Sensitivity and Uncertainty Anàlysis for Linear Functionals of the Time-Dependent Nuclide Density Field," ORNL/TM-5799 (1977).

20. A. Gandini, "A Method of Correlation of Burnup Measurements for Physics Prediction of Fast Reactor L1fe," Nucl. Sci. Eny. 38, 1-7 (1969).

21. M. Becker, "Perturbation Theory for Ratios in Linear and Non-linear Problems", Nucl. Sci. Eng. 62, 296 (1977).

22. C. R. Weisbin et al, "Application of Sensitivity and Uncertainty Methodology to Fast Reactor Integral Experiment Analysis", Nucl. Sci. Eng. 66 (1978). 
ORNL/TM-6303

Distribution Category UC-79d

Breeder Reactor Physics

\section{INTERNAL DISTRIBUTION}

$\begin{array}{ll}\text { 1. L. S. Abbott } \\ \text { 2. R. G. Alsmiller } \\ \text { 3. V. C. Baker } \\ \text { 4. D. E. Bartine } \\ \text { 5. M. A. Bjerke } \\ \text { 6. T. F. Bott } \\ \text { 7. T. J. Burns } \\ \text { 8. } & \text { D. G. Cacuci } \\ \text { 9. R. L. Childs } \\ \text { 10. S. N. Cramer } \\ \text { 11. G. de Saussure } \\ \text { 12. L. Dodds } \\ \text { 13. W. W. Engle } \\ \text { 14. G. F. Flanagan } \\ \text { 15. T. B. Fowler } \\ \text { 16. T. A. Gabriel } \\ \text { 17. H. Goldstein (consultant) } \\ \text { 18. } & \text { N. M. Greene } \\ \text { 19. P. M. Haas } \\ \text { 20. T. J. Hoffman } \\ \text { 21. } \text { D. T. Ingersoll } \\ \text { 22. R. A. Lillie } \\ \text { 23. J. L. Lucius } \\ \text { 24. R. E. Maerker } \\ \text { 25. F. C. Maienschein } \\ \text { 26. J. H. Marable } \\ \text { 27. B. F. Maskewitz } \\ \text { 28. J. M. McAdoo } \\ \end{array}$

29. F. R. Mynatt

30-49. E. M. Oblow

50. J. V. Pace

51. P. Patriarca

52. R. W. Peelle

53. F. G. Perey

54. R. B. Perez

55. W. A. Rhoades

56. R. W. Roussin

57. R. T. Santoro

58. E. T. Toml inson

59. D. R. Vondy

60. C. R. Weisbin

61. R. M. Westfall

62. J. E. White

63. G. E. Whitesides

64. M. L. Williams

65. A. Zucker

66. Paul Greebler (consultant)

67. W. Loewenste in (consultant)

68. R. E. Uhrig (consultant)

69. R. Wilson (consultant)

70-71. Central Research Library

72. $Y-12$ Document Reference Section

73-74. Laboratory Records Department

75. Laboratory Records, ORNL-RC

76. ORNL Patent Office

\section{EXTERNAL DISTRIBUTION}

77-78. Director, Division of Reactor Research and Technology, DOE, Washington, DC 20545

79. Director, Research and Technical Support Divisicn, DOE-ORC.

80. Director, Reactor Division, DOE-ORO

81-307. Given distribution as shown in TID-4500, Distribution Category UC-79d - Breeder Reactor Physics (Base) 